\title{
INFLUENCE OF HEAVY METAL CONCENTRATION ON CHLOROPHYLL CONTENT IN Pleurozium schreberi MOSSES
}

\begin{abstract}
The aim of biomonitoring is assessment of environment condition. Biomonitoring studies with the use of mosses focus mainly on analytes accumulation and determining elements' concentrations in the study area. It is often forgotten that a bioindicator should be alive during biomonitoring studies (which can be determined by, e.g., analysis of chlorophyll content). The objective of the carried out research was an assessment of the influence of selected heavy metals concentration: $\mathrm{Ni}, \mathrm{Cu}, \mathrm{Zn}, \mathrm{Cd}$ and $\mathrm{Pb}$ accumulated by Pleurozium schreberi mosses during 3-month exposition within active biomonitoring, on their vitality, assessed by an analysis of $a$ and $b$ chlorophyll concentrations. The studies were also carried out in laboratory conditions, where the content of the dyes was determined with the aid of a UV-Vis spectrophotometer, in mosses reacting with solutions of various concentrations of the analysed metals. The content of elements in mosses after exposition and in solutions prior and after sorption were determined with the use of atomic absorption spectrometry (AAS) in a flame atomiser. After the carried out studies it was determined that mosses, during 12-week long exposition, accumulated heavy metals, which did not clearly influence the changes in chlorophyll content. The carried out studies prove that heavy metals are not the only and determining factor, which influences chlorophyll content in mosses as well as the bioindicator's vitality in the conditions of environmental stress.
\end{abstract}

Keywords: active biomonitoring, mosses, heavy metals, chlorophyll content

\section{Introduction}

Various live organisms are used in assessment of, for example, ecosystems pollution with heavy metals [1-3]. Much attention is focused on accumulation of analytes by indicator species, whether in the field studies $[4,5]$, or in laboratory conditions $[6,7]$.

Biomonitoring with the use of mosses is applied in assessment of natural environment pollution with any substances (e.g. heavy metals, PAHs or microplastic) [8-10] and has been used since the end of 1960s - the studies were initiated by two Swedish scientists [11]. A number of projects have been initiated since that time, which support biological monitoring; one of these is ICP Vegetation, in which most European countries participate and which assesses the influence of air pollution on cultivation and (semi)natural plants $[12,13]$. Both studies of passive and active biomonitoring evolve, in order to become standardised studies [14, 15] which can compete with instrumental methods [16].

The definition of biomonitoring needs particular attention. The concept of "biomonitoring" involves the use of live organisms (or their tissues) in assessment of environment condition in the qualitative sense, or the changes, which took place in

\footnotetext{
${ }^{1}$ Institute of Environmental Engineering and Biotechnology, University of Opole, ul. kard. B. Kominka 6a, 45-032 Opole, Poland, phone +48 7740160 42, fax +48 774016051

*Corresponding author: swislowskip@gmail.com
} 
environment, caused by e.g. anthropopressure [17]. The important role of bioindicator, which should be live during an experiment (unpublished data) should be emphasised, and [18]. Studies with devitalised samples are in conflict with the above presented definition of biomonitoring, even considering sometimes better sorption characteristics than live samples $[19,20]$. Chlorophyll content is one of the parameters, which may define bioindicator's vitality during studies $[21,22]$. It is a quite commonly studied photosynthetic dye and its content is determined in reference to concentration of, e.g. a particular metal [23, 24]. Analytes contained in solutions have a general negative influence on mosses by, e.g. modification and structural changes of cell wall [25, 26]. However, sometimes chlorophyll content increases versus concentration of a given pollutant, for inexplicable reasons $[27,28]$.

Nevertheless, a large part of studies focuses only on the accumulation of selected elements by mosses, where large concentrations of metals are determined in various species, however, authors do not inform about the parameters of life functions [29-31]. In the context of biomonitoring studies it should be remembered that mosses are not only chemical adsorbent but also living organisms [32]. That is why biomonitoring studies with the use of mosses should focus on monitoring of their life parameters, such as, for example, chlorophyll content or fluorescence [33].

The aim of the carried out research was to asses: (I) vitality of mosses (based on the measured chlorophyll content) during 3-month exposition in active biomonitoring and (II) the influence of concentration of the selected heavy metals on the content of this photosynthetic dye in mosses, during the carried out laboratory experiment.

\section{Material and methods}

The species used for this study was the moss Pleurozium schreberi. It was collected in spring 2020 from forests in the Swietokrzyskie Province, Poland (PL). Moss samples were taken and prepared before exposure as part of active biomonitoring in accordance with the guidelines [13, 34]. Mosses were exposed in the centre of Opole, Opolskie Province, PL. For analyses on chlorophyll content in mosses was measured using a Cary $3500 \mathrm{UV}$-Vis Compact Peltier spectrophotometer from Agilent Technologies (USA). Mosses $(0.100 \pm 0.001 \mathrm{~g})$ were ground in a porcelain mortar with $5 \mathrm{~cm}^{3}$ pure acetone. Then samples were centrifuged (10 minutes, $10,000 \mathrm{rpm})$. Each measurement was made in 5 replicants. Chlorophyll- $a$ and chlorophyll- $b$ analytical standards (ChromaDex, USA, certified dye content $>97 \%$ ) were used to calibrate spectrophotometer. Based on the obtained absorbance values, the chlorophyll concentrations were calculated using the extinction coefficients and equation using a spectrophotometer at two wavelengths, 662 and $645 \mathrm{~nm}$, for maximum absorption of chlorophyll- $a$ and $-b$, respectively [35].

In order to determine the heavy metals, after 3-months exposure (summer 2020), each moss sample $(n=12$, repl. $=3)$, with a mass of $1.000 \pm 0.001 \mathrm{~g}$ dry mass (d.m.), was mineralised in a mixture of nitric $\operatorname{acid}(\mathrm{V})\left[\mathrm{HNO}_{3} 65 \%\right]$ and hydrogen peroxide $\left[\mathrm{H}_{2} \mathrm{O}_{2} 37 \%\right]$ using a Speedwave Four Berghof, DE microwave oven. The mineralisation process was carried out at a temperature of $180{ }^{\circ} \mathrm{C}$. Heavy metals were determined using an atomic absorption flame spectrometer (F-AAS) type iCE 3500 (series 3000) made by Thermo Scientific, USA. The results were converted into $1 \mathrm{~kg}$ of sample. Calibration of the spectrometer was performed with a standard solution from ANALYTIKA Ltd. (CZ). The values of the highest concentrations of the models used for calibration $\left(5 \mathrm{mg} / \mathrm{dm}^{3}\right.$ for 
$\mathrm{Ni}, \mathrm{Cu}, \mathrm{Zn}, \mathrm{Pb}, 2 \mathrm{mg} / \mathrm{dm}^{3}$ for $\mathrm{Cd}$ ) were approved as linear limits to signal dependence on concentration. Concentrations of metals were determined in solution after mineralisation and dilution and were filtered into volumetric flasks of $25 \mathrm{~cm}^{3}$. In Table 1, the instrumental detection limits $(I D L)$ and instrumental quantification limits $(I Q L)$ for the spectrometer iCE 3500 are presented.

The instrumental detection limits $(I D L)$ and instrumental quantification limits $(I Q L)$

Table 1 for the iCE 3500 spectrometer $\left[\mathrm{mg} / \mathrm{dm}^{3}\right]$ [36]

\begin{tabular}{|c|c|c|}
\hline Metal & $\boldsymbol{I D L}$ & $\boldsymbol{I Q L}$ \\
\hline $\mathrm{Ni}$ & 0.0043 & 0.050 \\
\hline $\mathrm{Cu}$ & 0.0045 & 0.033 \\
\hline $\mathrm{Zn}$ & 0.0033 & 0.010 \\
\hline $\mathrm{Cd}$ & 0.0028 & 0.013 \\
\hline $\mathrm{Pb}$ & 0.0130 & 0.070 \\
\hline
\end{tabular}

The RAF - Relative Accumulation Factors was used to determine increases of concentrations of the analytes in the exposed mosses samples [4].

Additionally, the influence of the selected concentrations of heavy metals on chlorophyll content in mosses was analysed in laboratory conditions. Moss samples for the analysis were rinsed in demineralised water (conductivity $\kappa=0.5 \mu \mathrm{S} / \mathrm{cm}$ ) and dried at room temperature $(24 \mathrm{~h})$ [34]. The prepared moss samples with the mass of $0.200 \pm 0.001 \mathrm{~g} \mathrm{~d} . \mathrm{m}$. were placed in $200 \mathrm{~cm}^{3}$ of the solution of salt of the selected analyte: $\mathrm{Ni}, \mathrm{Cu}, \mathrm{Zn}, \mathrm{Cd}$ and $\mathrm{Pb}$. The studies were carried out also with the use of a mixture of the analysed metals. The process was carried out for $60 \mathrm{~min}$, stirring the solution. After exposition, moss samples were rinsed in demineralised water (conductivity $\kappa=0.5 \mu \mathrm{S} / \mathrm{cm}$ ) and dried at room temperature $(24 \mathrm{~h})$. Before and after the process, concentrations of heavy metals in the solutions were determined using an atomic absorption flame spectrometer (F-AAS) type iCE 3500 and analyses on chlorophyll content in mosses was measured using a Cary 3500 UV-Vis spectrophotometer.

Concentrations of the selected heavy metals were selected based on literature on analytes concentrations in particulate matter PM10 and PM2.5.

Microsoft Excel 2016 and STATISTICA ver. 13.3 software were used to process the data. Shapiro Wilk's test was used to assess the normality of the data. Spearman's rho test was used to analyse the correlations between metal concentrations and chlorophyll content.

\section{Results and discussion}

The results of biomonitoring studies were presented in Table 2 and Figure 1. In Table 2 the results of concentrations of heavy metals determined in mosses after each week of exposition as well as the calculated $R A F$ values are presented.

The results in Table 2 indicate that mosses accumulated selected heavy metals. Concentration of nickel was below the limit of quantification of the applied analytical technique, therefore the content of this analyte was not provided, similarly to cadmium in the last 3 weeks of exposition. In other cases, heavy metals concentrations were the highest during the last month of exposition. The $R A F$ values, which are the highest in the last month of the experiment duration, also confirm the fact. The $R A F$ factor was not 
determined for $\mathrm{Cd}$, due to the lowest concentration of the metal in mosses throughout the whole study period, versus the control sample (not exposed).

Table 2

Average concentrations of heavy metals [mg/kg d.m.] determined in mosses after 12-week exposition period and calculated values of $R A F$ factor [-]

\begin{tabular}{|c|c|c|c|c|c|c|c|}
\hline $\begin{array}{c}\text { Time } \\
\text { [weeks] }\end{array}$ & $\mathbf{C u}$ & $\boldsymbol{R} \boldsymbol{A} \boldsymbol{F}_{\mathbf{C u}}$ & $\mathbf{Z n}$ & $\boldsymbol{R A F}_{\mathbf{Z n}}$ & $\mathbf{C d}$ & $\mathbf{P b}$ & $\boldsymbol{R A F}_{\mathbf{P b}}$ \\
\hline 0 & 5.92 & - & 61.4 & - & 1.13 & 5.48 & - \\
\hline 1 & 6.42 & 0.085 & 57.6 & 0.00 & 0.475 & 5.55 & 0.012 \\
\hline 2 & 6.80 & 0.149 & 57.4 & 0.00 & 0.517 & 6.41 & 0.169 \\
\hline 3 & 6.53 & 0.103 & 57.9 & 0.00 & 0.458 & 5.29 & 0.00 \\
\hline 4 & 7.43 & 0.254 & 62.1 & 0.011 & 0.465 & 6.18 & 0.126 \\
\hline 5 & 7.59 & 0.281 & 68.8 & 0.122 & 0.390 & 6.10 & 0.111 \\
\hline 6 & 7.42 & 0.253 & 61.7 & 0.005 & 0.413 & 6.78 & 0.236 \\
\hline 7 & 5.91 & 0.00 & 57.0 & 0.00 & 0.495 & 6.39 & 0.164 \\
\hline 8 & 6.72 & 0.135 & 65.4 & 0.065 & 0.493 & 8.47 & 0.544 \\
\hline 9 & 6.85 & 0.156 & 66.0 & 0.076 & 0.535 & 10.3 & 0.874 \\
\hline 10 & 11.5 & 0.938 & 102 & 0.654 & & 119 & 20.7 \\
\hline 11 & 8.56 & 0.447 & 59.4 & 0.00 & & 8.59 & 0.566 \\
\hline 12 & 11.9 & 1.01 & 80.4 & 0.310 & $*$ & 56.8 & 9.35 \\
\hline
\end{tabular}

*below the limit of quantification

In Figure 1, changes in chlorophyll $a$ (Chl-a) and chlorophyll $b$ (Chl-b) concentrations in mosses during their 3-month long exposition, are presented.

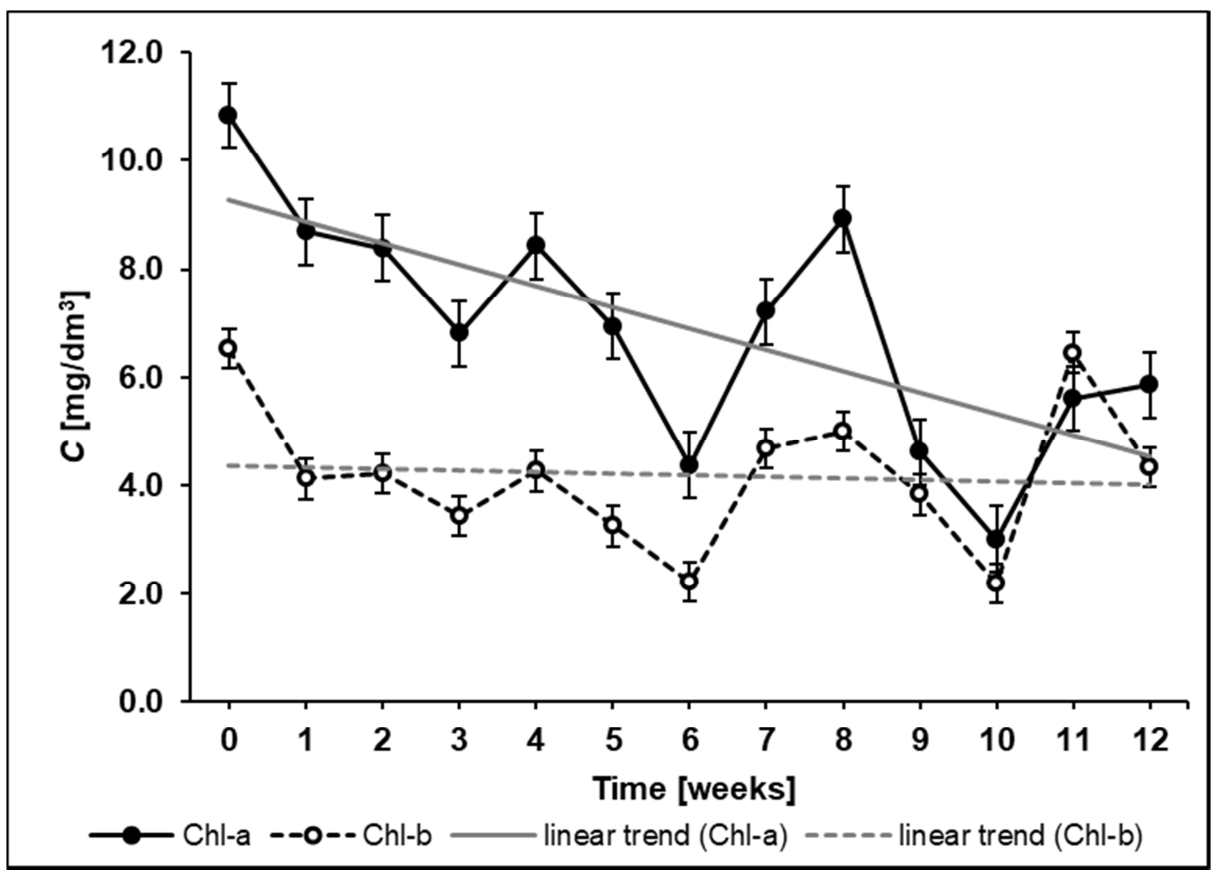

Fig. 1. Changes of chlorophyll concentrations in mosses during exposition; whiskers represent standard error 
Chlorophyll $a$ and $b$ content presented in Figure 1 indicate that concentration of this dye varied during the experiment. Despite the increase of chlorophyll content in $4^{\text {th }}, 7^{\text {th }}, 8^{\text {th }}$ and $11^{\text {th }}$ week of the study for both types of chlorophyll, the trend is decreasing. After 3 months of exposition, taking the average chlorophyll content, the concentration dropped by over $60 \%$. However, comparing the concentration values of heavy metals with chlorophyll $a$ content during the studied period, the correlation $\left(r_{\mathrm{s}}\right)$ for $\mathrm{Cu}, \mathrm{Zn}, \mathrm{Cd}$ and $\mathrm{Pb}$ is, respectively: $-0.615,-0.579,0.721$ and -0.584 . No correlation was identified for chlorophyll $b$.

The second stage of the study involved laboratory experiments, aiming at assessment of the influence of the selected concentrations of heavy metals on chlorophyll content in mosses. Mosses were exposed to metals salts solutions, with concentrations selected on the basis of the analysis of literature on the content of these analytes in particulate matter. The limits of quantification of the used AAS apparatus were also taken into consideration. Table 3 presents heavy metal concentrations prior and after the sorption process in mosses.

Summary of heavy metals concentrations during sorption of analytes by mosses $\left[\mathrm{mg} / \mathrm{dm}^{3}\right]$

\begin{tabular}{|c|c|c|c|c|c|c|c|c|c|c|}
\hline $\begin{array}{c}\text { No. of } \\
\text { con. }\end{array}$ & \multicolumn{2}{|c|}{ Ni } & \multicolumn{2}{c|}{ Cu } & \multicolumn{2}{c|}{ Zn } & \multicolumn{2}{c|}{ Cd } & \multicolumn{2}{c|}{ Pb } \\
\hline & $C_{0}$ & $C_{1}$ & $C_{0}$ & $C_{1}$ & $C_{0}$ & $C_{1}$ & $C_{0}$ & $C_{1}$ & $C_{0}$ & $C_{1}$ \\
\hline $\mathbf{I}^{\circ}$ & 0.074 & $<0.05$ & 0.034 & $<0.033$ & 0.054 & 0.020 & 0.029 & $<0.013$ & 0.092 & $<0.07$ \\
\hline II $^{\circ}$ & 0.354 & $<0.05$ & 0.301 & $<0.033$ & 0.445 & 0.024 & 0.304 & $<0.013$ & 0.242 & $<0.07$ \\
\hline III $^{\circ}$ & 3.25 & 0.559 & 3.16 & 0.286 & 4.07 & 0.621 & 2.70 & 0.102 & 2.70 & $<0.07$ \\
\hline
\end{tabular}

No. of con. - number of concentration; $C_{0}$ - concentration prior to sorption; $C_{1}$ - concentration after sorption

The sorption results from Table 3 indicate very good accumulation of heavy metals in mosses. In the case of the first two concentrations after the process, for the majority of analytes, their concentration in a solution was below the quantification limit of the applied analytical technique. In the case of concentration III $^{\circ}$ there was approximately $83 \%$ reduction of $\mathrm{Ni}$ and approximately $90 \%$ of other elements from their salts solutions (i.e. sorption in mosses).

Figure 2 presents the influence of individual heavy metal concentrations on absorbance value (Abs).

As can be seen in Figure 2 individual concentrations of heavy metals cause reduction of absorbance value (ergo chlorophyll concentration after recalculation - Table 4) in mosses, versus control sample. However, there is no strict correlation between the type and concentration of an element and the absorbance value. As can be seen in Figure $2 \mathrm{a}$, the lowest absorbance was at concentration $\mathrm{III}^{\circ}$ and in tow other cases at concentration $\mathrm{I}^{\circ}$, even though it was expected that the highest concentration of an analyte would cause the largest decrease of absorbance value at the same time. Further results from this part of the experiment are presented in Table 4. 
a)

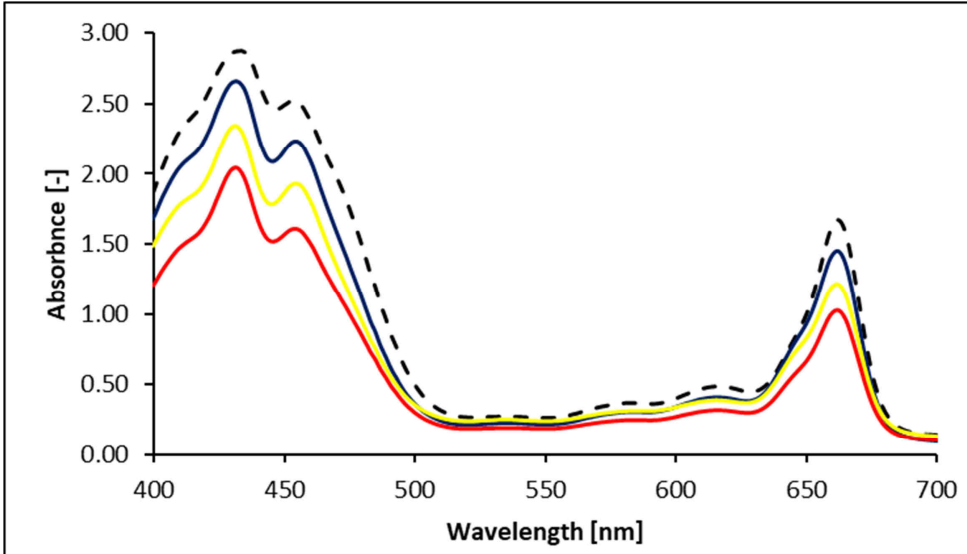

b)

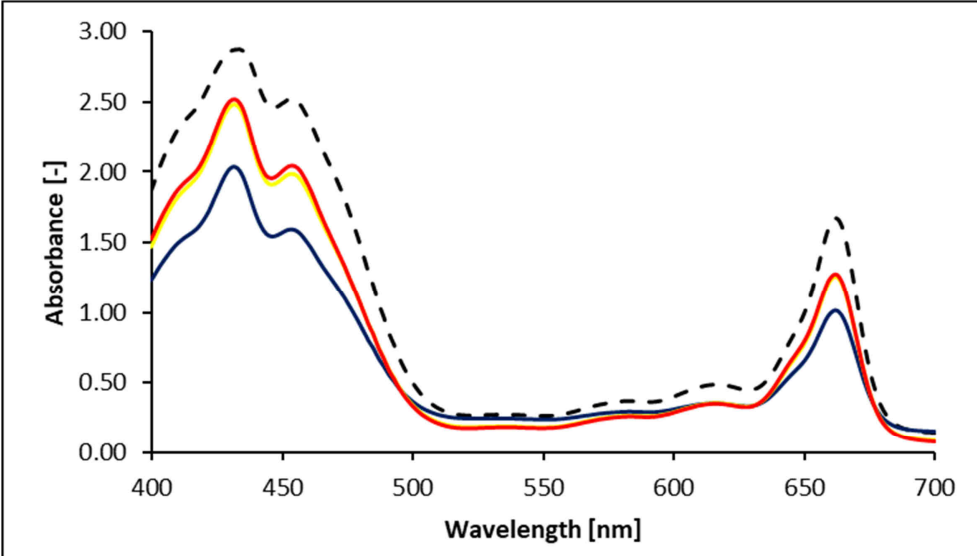

c)

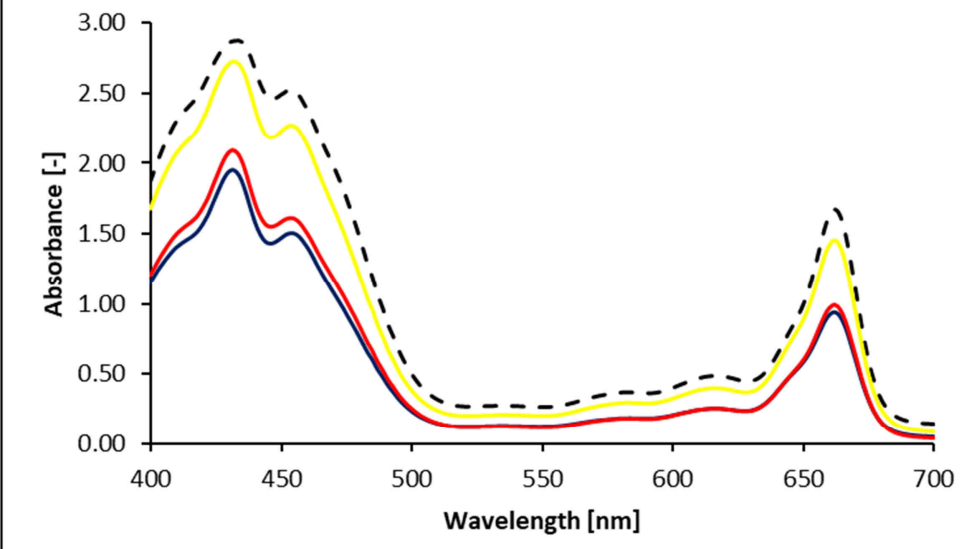

Fig. 2. Changes of absorbance depending on metal concentration: a) zinc, b) lead and c) cadmium (dotted line is control sample, blue line is concentration $\mathrm{I}^{\circ}$, yellow line is concentration $\mathrm{II}^{\circ}$, red line is concentration $\mathrm{III}^{\circ}$ ) 
Chlorophyll content in mosses during laboratory experiment $\left[\mathrm{mg} / \mathrm{dm}^{3}\right]$

\begin{tabular}{|c|c|c|c|c|c|c|c|c|c|c|}
\hline \multirow{2}{*}{$\begin{array}{c}\text { No. of } \\
\text { con. }\end{array}$} & \multicolumn{2}{|c|}{ Ni } & \multicolumn{2}{c|}{ Cu } & \multicolumn{2}{c|}{ Zn } & \multicolumn{3}{c|}{ Cd } & \multicolumn{2}{c|}{ Pb } \\
\hline & Chl- $a$ & Chl- $b$ & Chl- $a$ & Chl- $b$ & Chl- $a$ & Chl- $b$ & Chl- $a$ & Chl- $b$ & Chl- $a$ & Chl- $b$ \\
\hline $\mathbf{0}$ & 17.7 & 8.54 & 17.7 & 8.54 & 17.7 & 8.54 & 17.7 & 8.54 & 17.7 & 8.54 \\
\hline $\mathbf{I}^{\circ}$ & 14.7 & 7.77 & 17.0 & 9.28 & 15.2 & 8.91 & 9.87 & 5.29 & 10.6 & 6.32 \\
\hline II $^{\circ}$ & 8.22 & 5.26 & 21.6 & 12.8 & 12.5 & 8.51 & 15.3 & 7.79 & 13.3 & 7.06 \\
\hline III $^{\circ}$ & 8.67 & 5.91 & 18.3 & 10.2 & 10.7 & 6.43 & 10.5 & 5.17 & 13.4 & 7.30 \\
\hline
\end{tabular}

No. of con. - number of concentration; 0 - control sample; Chl- $a$ - chlorophyll $a$; Chl- $b$ - chlorophyll $b$

The results presented in the above table confirm previously presented results (Fig. 2). The type of analyte and its concentration do not clearly influence the decrease of chlorophyll $a$ and $b$ content. Generally, metals cause reduction of chlorophyll content in mosses, however, in the case of chlorophyll $a$ and $b$, copper in concentrations $\mathrm{I}^{\circ}, \mathrm{II}^{\circ}$ and $\mathrm{III}^{\circ}$ and in the case of chlorophyll $b$, zinc (concentration $\mathrm{I}^{\circ}$ ) cause the increase of this dye content.

An additional experiment was carried out, during which mosses were treated with a mixture of the analysed heavy metals in the defined concentrations, as above. The results of sorption of each metal by mosses were presented in Table 5 .

Concentrations of heavy metals prior and after sorption by mosses from the elements $\mathrm{mix}\left[\mathrm{mg} / \mathrm{dm}^{3}\right]$

\begin{tabular}{|c|c|c|c|c|c|c|c|c|c|c|}
\hline $\begin{array}{c}\text { No. of } \\
\text { con. }\end{array}$ & \multicolumn{2}{|c|}{ Ni } & \multicolumn{2}{c|}{ Cu } & \multicolumn{2}{c|}{ Zn } & \multicolumn{2}{c|}{ Cd } & \multicolumn{2}{c|}{ Pb } \\
\hline & $C_{0}$ & $C_{1}$ & $C_{0}$ & $C_{1}$ & $C_{0}$ & $C_{1}$ & $C_{0}$ & $C_{1}$ & $C_{0}$ & $C_{1}$ \\
\hline $\mathbf{I}^{\circ}$ & 0.051 & $<0.05$ & 0.040 & $<0.033$ & 0.013 & $<0.01$ & 0.050 & $<0.013$ & 0.071 & $<0.07$ \\
\hline II $^{\circ}$ & 0.388 & $<0.05$ & 0.471 & $<0.033$ & 0.561 & 0.046 & 0.996 & 0.058 & 1.17 & 0.076 \\
\hline III $^{\circ}$ & 3.04 & 1.66 & 2.63 & 0.481 & 3.33 & 1.80 & 2.27 & 1.09 & 2.35 & 0.337 \\
\hline
\end{tabular}

No. of con. - number of concentration; $C_{0}$ - concentration prior to sorption; $C_{1}$ - concentration after sorption

The results from Table 5 indicate that moss Pleurozium schreberi sorbs individual analytes from the mix. In the case of concentration III $^{\circ}$ there was approximately $45 \%$ reduction of $\mathrm{Ni}$ and approximately $90 \%$ of other elements from their salts solutions. The reduction of nickel sorption efficiency was influenced by the competitive sorption of other elements from the mix.

The graph in Figure 3 presents changes in absorbance, depending on the concentration of the used analytes mix.

The above presented study results indicate that metal mix, depending on concentration, influences reduction of absorbance content, however, it cannot be concluded that the highest concentration causes the highest reduction of absorbance value. In this case, for mosses the lowest absorbance values, ergo chlorophyll content, were caused by the analytes mix solution with concentration $\mathrm{II}^{\circ}$.

Laboratory studies proved that mosses influenced by heavy metals in the concentrations equal or higher than their concentrations in particulate matter can cause decrease of chlorophyll content in mosses, however, the bioindicator still had features of a living organism. 


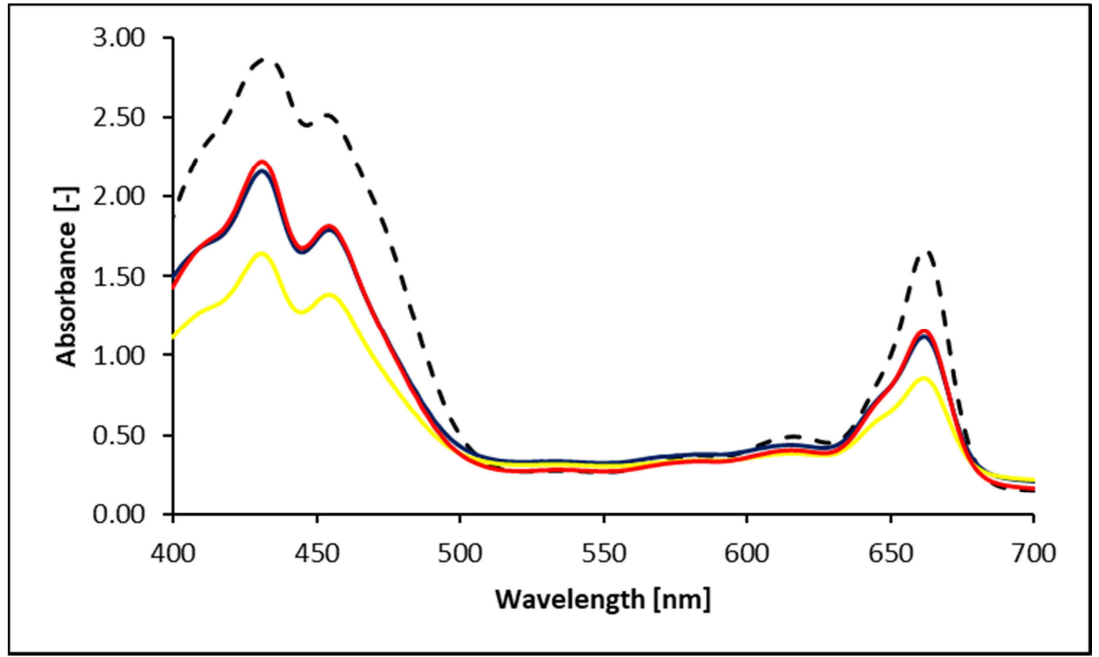

Fig. 3. Changes in absorbance depending on the applied mix (dotted line is control sample, blue line is concentration $\mathrm{I}^{\circ}$, yellow line is concentration $\mathrm{II}^{\circ}$, red line is concentration $\mathrm{III}^{\circ}$ )

Mosses are a useful tool in monitoring environment quality and identifying pollution sources [37]. The selected species has been used as bioindicator in active biomonitoring studies [38, 39] and is capable of accumulating mainly copper and remove its ions from solutions [40, 41]. Our biomonitoring (field) studies did not confirm large accumulation of this metal, however, this may be due to the fact that concentrations of heavy metals accumulated in mosses depended on the time and place of samples exposition [42]. There are a number of factors, which will influence the process of analytes sorption by mosses and the content of heavy metals in mosses [43]. Other researchers confirm that along with the duration/increase of exposition time to pollution, chlorophyll content in mosses decreases [44, 45]. The main factor, which causes reduction of chlorophyll content, is general environmental stress [46, 47]. During exposition and in other than natural conditions, moss enters cryptobiosis [18] - a condition of low metabolic activity, ergo limitation of life functions. This phenomenon in biomonitoring was practically not studied and it needs to be verified, in order to determine when and to what extent it influences the possibility of elements sorption by mosses [2, 48, 49].

\section{Conclusion}

The carried out research proved that $P$. schreberi mosses can be a quality bioindicator of atmospheric aerosol in urban areas. During a field experiment, mosses accumulated analytes, which could be observed the following weeks, indicating growing/changing air pollution in the study location. During the exposition, content of chlorophyll $a$ and $b$ decreased, however, during a 3-month period of environmental stress and exposition to pollution, they demonstrated features of a living organism (presence of chlorophyll). Laboratory experiment demonstrated good sorption characteristics of mosses with analytes from both single-element solutions and mixtures and confirmed yet again that mosses can be used in removing and accumulation of heavy metals. No correlation between changes in chlorophyll content and an element concentration were determined in this part of the 
experiment. This demonstrated complexity of the factors, which influence vitality of moss during biomonitoring studies. It was determined that mosses under the influence of heavy metals in concentrations equal or higher than their concentrations in particulate matter still demonstrate characteristics of a living organism.

The studies on the assessment and monitoring of life parameters should be extended, with the use of, for example, chlorophyll fluorescence and measurement of actual photochemical efficiency [Y(II)] or maximum quantum yield (Fv/Fm). Attention should also be paid to the studies on mosses entering the state of cryptobiosis and its consequences.

\section{Acknowledgements}

We would like to thank for the invaluable help and support of Jerzy Czachórski from Perlan Technologies Poland Sp. z o.o. for lending a Cary 3500 UV-Vis Compact Peltier spectrophotometer from Agilent Technologies for studies and to thank him for his contribution.

\section{References}

[1] Rajfur M. Algae - Heavy metals biosorbent. Ecol Chem Eng S. 2013;20(1):23-40. DOI: 10.2478/eces-2013-0002.

[2] Mahapatra B, Dhal NK, Dash AK, Panda BP, Panigrahi KCS, Pradhan A. Perspective of mitigating atmospheric heavy metal pollution: using mosses as biomonitoring and indicator organism. Environ Sci Pollut Res. 2019;26:29620-38. DOI: 10.1007/s11356-019-06270-z.

[3] Jóźwiak MA, Jóźwiak M. Influence of cement industry on accumulation of heavy metals in bioindicators. Ecol Chem Eng S. 2009;16:323-34. Available from: https://drive.google.com/file/d/ 16kMQeMGRupbWPc4yhlKh48Uy2wH3g2vG/view.

[4] Zinicovscaia I, Urošević MA, Vergel K, Vieru E, Frontasyeva MV, Povar I, et al. Active moss biomonitoring of trace elements air pollution in Chisinau, Republic of Moldova. Ecol Chem Eng S. 2018;25:361-72. DOI: 10.1515/eces-2018-0024.

[5] Agnan Y, Séjalon-Delmas N, Claustres A, Probst A. Investigation of spatial and temporal metal atmospheric deposition in France through lichen and moss bioaccumulation over one century. Sci Total Environ. 2015;529:285-96. DOI: 10.1016/j.scitotenv.2015.05.083.

[6] Wu Q, Xian Y, He Z, Zhang Q, Wu J, Yang G, et al. Adsorption characteristics of Pb(II) using biochar derived from spent mushroom substrate. Sci Rep. 2019;9:1-11. DOI: 10.1038/s41598-019-52554-2.

[7] Mondal NK, Kundu M. Biosorption of fluoride from aqueous solution using lichen and its Ca-pretreated biomass. Water Conserv Sci Eng. 2016;1:143-60. DOI: 10.1007/s41101-016-0009-8.

[8] Konopka Z, Świsłowski P, Rajfur M. Biomonitoring of atmospheric aerosol with the use of Apis mellifera and Pleurozium schreberi. Chem Didact Ecol Metrol. 2019;24:107-16. DOI: 10.2478/cdem-2019-0009.

[9] Yakovleva EV, Gabov DN, Beznosikov VA, Kondratenok BM. Accumulation of polycyclic aromatic hydrocarbons in soils and mosses of southern tundra at different distances from the thermal power plant. Eurasian Soil Sci. 2018;51:528-35. DOI: 10.1134/S1064229318030134.

[10] Roblin B, Aherne J. Moss as a biomonitor for the atmospheric deposition of anthropogenic microfibres. Sci Total Environ. 2020;715:136973. DOI: 10.1016/j.scitotenv.2020.136973.

[11] Rühling A, Tyler G. An ecological approach to the lead problem. Bot Not. 1968;121:3.

[12] Napa Ü, Kabral N, Liiv S, Asi E, Timmusk T, Frey J. Current and historical patterns of heavy metals pollution in Estonia as reflected in natural media of different ages: ICP Vegetation, ICP Forests and ICP Integrated Monitoring data. Ecol Indic. 2015;52:31-9. DOI: 10.1016/j.ecolind.2014.11.028.

[13] ICP Vegetation. Heavy metals, nitrogen and POPs in European mosses: 2020 Survey. 2020. Available from: https://icpvegetation.ceh.ac.uk/sites/default/files/ICP\%20Vegetation $\% 20$ moss $\% 20$ monitoring\%20manual\%2 02020.pdf.

[14] Fernández JA, Boquete MT, Carballeira A, Aboal JR. A critical review of protocols for moss biomonitoring of atmospheric deposition: Sampling and sample preparation. Sci Total Environ. 2015;517:132-50. DOI: 10.1016/j.scitotenv.2015.02.050. 
[15] Ares A, Fernández JA, Carballeira A, Aboal JR. Towards the methodological optimization of the moss bag technique in terms of contaminants concentrations and replicability values. Atmos Environ. 2014;94:496-507. DOI: 10.1016/j.atmosenv.2014.05.066.

[16] Vuković G, Aničić Uroševic M, Razumenić I, Kuzmanoski M, Pergal M, Škrivanj S, et al. Air quality in urban parking garages (PM10, major and trace elements, PAHs): Instrumental measurements vs. active moss biomonitoring. Atmos Environ. 2013;85:31-40. DOI: 10.1016/j.atmosenv.2013.11.053.

[17] Markert B. From biomonitoring to integrated observation of the environment - The multi-markered bioindication concept. Ecol Chem Eng S. 2008;15:315-33. Available from: http://tchie.uni.opole.pl/freeECE/S_15_3/Markert_15(S3).pdf.

[18] Capozzi F, Sorrentino MC, Di Palma A, Mele F, Arena C, Adamo P, et al. Implication of vitality, seasonality and specific leaf area on PAH uptake in moss and lichen transplanted in bags. Ecol Indic. 2020;108:105727. DOI: 10.1016/j.ecolind.2019.105727.

[19] Debén S, Fernández JA, Carballeira A, Aboal JR. Using devitalized moss for active biomonitoring of water pollution. Environ Pollut. 2016;210:315-22. DOI: 10.1016/j.envpol.2016.01.009.

[20] Cesa M, Bizzotto A, Ferraro C, Fumagalli F, Luigi Nimis P. Oven-dried mosses as tools for trace element detection in polluted waters: A preliminary study under laboratory conditions. Plant Biosyst. 2011;145:832-40. DOI: 10.1080/11263504.2011.580790.

[21] Chen Y, Yuan M, Zhang H, Zeng X, Liu H, Du X. Influences of cu and cr stress on antioxidant system and chlorophyll fluorescence in terrestrial moss taxiphyllum taxirameum. Fresenius Environ Bull. 2015;24:2211-9. https://www.prt-parlar.de/download/.

[22] Rastogi A, Antala M, Gąbka M, Rosadziński S, Stróżecki M, Brestic M, et al. Impact of warming and reduced precipitation on morphology and chlorophyll concentration in peat mosses (Sphagnum angustifolium and S. fallax). Sci Rep. 2020;10:1-9. DOI: 10.1038/s41598-020-65032-x.

[23] Shakya K, Chettri MK, Sawidis T. Impact of heavy metals (copper, zinc, and lead) on the chlorophyll content of some mosses. Arch Environ Contam Toxicol. 2008;54:412-21. DOI: 10.1007/s00244-007-9060-y.

[24] Kováčik J, Klejdus B, Štork FŠ, Hedbavny J. Physiological responses of Tillandsia albida (Bromeliaceae) to long-term foliar metal application. J Hazard Mater. 2012;239-240:175-82. DOI: 10.1016/j.jhazmat.2012.08.062.

[25] Krzesłowska M, Rabęda I, Lewandowski M, Samardakiewicz S, Basińska A, Napieralska A, et al. Pb induces plant cell wall modifications - In particular - The increase of pectins able to bind metal ions level. E3S Web Conf. 2013;1:2-4. DOI: 10.1051/e3sconf/20130126008.

[26] Itouga M, Hayatsu M, Sato M, Tsuboi Y, Kato Y, Toyooka K, et al. Protonema of the moss Funaria hygrometrica can function as a lead $(\mathrm{Pb})$ adsorbent. PLoS One. 2017;12:1-19. DOI: 10.1371/journal.pone.0189726.

[27] Aydoğan S, Erdağ B, Yildiz Aktaş L. Bioaccumulation and oxidative stress impact of $\mathrm{Pb}, \mathrm{Ni}, \mathrm{Cu}$, and $\mathrm{Cr}$ heavy metals in two bryophyte species, Pleurochaete squarrosa and timmiella barbuloides. Turk J Botany. 2017;41:464-75. DOI: 10.3906/bot-1608-33.

[28] Lin X, Chen L, Hu X, Feng S, Huang L, Quan G, et al. Toxicity of graphene oxide to white moss Leucobryum glaucum. RSC Adv. Royal Soc Chem. 2017;7:50287-93. DOI: 10.1039/c7ra10096e.

[29] Pradhan A, Kumari S, Dash S, Biswal DP, Dash AK, Panigrahi KCS. Heavy metal absorption efficiency of two species of mosses (Physcomitrella patens and Funaria hygrometrica) studied in mercury treated culture under laboratory condition. IOP Conf Ser Mater Sci Eng. 2017;225. DOI: 10.1088/1757-899X/225/1/012225.

[30] Ogunkunle CO, Ziyath AM, Rufai SS, Fatoba PO. Surrogate approach to determine heavy metal loads in a moss species - Barbula lambaranensis. J King Saud Univ. 2016;28:193-7. DOI: 10.1016/j.jksus.2015.11.002.

[31] González AG, Pokrovsky OS. Metal adsorption on mosses: Toward a universal adsorption model. J Colloid Interface Sci. 2014;415:169-78. DOI: 10.1016/j.jcis.2013.10.028.

[32] Boquete MT, Aboal JR, Carballeira A, Fernández JA. Do mosses exist outside of Europe? A biomonitoring reflection. Sci Total Environ. 2017;593-594:567-70. DOI: 10.1016/j.scitotenv.2017.03.196.

[33] Liepiņa L, Ievinsh G. Potential for fast chlorophyll a fluorescence measurement in bryophyte ecophysiology. Est J Ecol. 2013;62:137-49. DOI: 10.3176/eco.2013.2.05.

[34] Świsłowski P, Kosior G, Rajfur M. The influence of preparation methodology on the concentrations of heavy metals in Pleurozium schreberi moss samples prior to use in active biomonitoring studies. Environ Sci Pollut Res. 2020. DOI: 10.1007/s11356-020-11484-7.

[35] Lichtenthaler HK, Wellburn AR. Determinations of total carotenoids and chlorophylls a and b of leaf extracts in different solvents. Biochem Soc Trans. 1983;11:591-2. Available from: https://portlandpress.com/biochemsoctrans/article-abstract/11/5/591/57549/Determinations-of-totalcarotenoids-and?redirectedFrom=fulltext. 
[36] Thermo Fisher Scientific Inc. iCE 3000 Series AA Spectrometers Operator's Manual. 2011;44:1-1 to 7-18. Available from: www.thermoscientific.com

[37] Krakovská AS, Svozilík V, Zinicovscaia I, Vergel K, Jančík P. Analysis of spatial data from moss biomonitoring in czech-polish border. Atmosphere. 2020;11:1-26. DOI: 10.3390/atmos11111237.

[38] Kosior G, Přibylová P, Vaňková L, Kukučka P, Audy O, Klánová J, et al. Bioindication of PBDEs and PCBs by native and transplanted moss Pleurozium schreberi. Ecotoxicol Environ Saf. 2017;143:136-42. DOI: 10.1016/j.ecoenv.2017.05.025.

[39] Samecka-Cymerman A, Kosior G, Kolon K, Wojtuń B, Zawadzki K, Rudecki A, et al. Pleurozium schreberi as bioindicator of mercury pollution in heavily industrialized region. J Atmos Chem. 2013;70:105-14. DOI: 10.1007/s10874-013-9256-7.

[40] Rumyantsev IV, Dunaev AM, Frontasyeva MV, Ostrovnaya TM. Interspecies comparison of elemental content in moss From Ivanovo region determined by NAA and AAS. XXI Int Semin on Interact Neutrons with Nucl (Fundamental Interact Neutrons, Nucl Struct Ultracold Neutrons, Relat Top Alushta, Ukr. 2013. Available from: http://isinn.jinr.ru/proceedings/isinn-21/pdf/rumyantsev.pdf.

[41] Grimm A, Zanzi R, Björnbom E, Cukierman AL. Comparison of different types of biomasses for copper biosorption. Bioresour Technol. 2008;99:2559-65. DOI: 10.1016/j.biortech.2007.04.036.

[42] Świsłowski P, Kříž J, Rajfur M. The use of bark in biomonitoring heavy metal pollution of forest areas on the example of selected areas in Poland. Ecol Chem Eng S. 2020;27(2):195-210. DOI: 10.2478/eces-2020-0013.

[43] Lequy E, Saby NPA, Ilyin I, Bourin A, Sauvage S, Leblond S. Spatial analysis of trace elements in a moss bio-monitoring data over France by accounting for source, protocol and environmental parameters. Sci Total Environ. 2017;590-591:602-10. DOI: 10.1016/j.scitotenv.2017.02.240.

[44] Varela Z, Roiloa SR, Fernández JA, Retuerto R, Carballeira A, Aboal JR. Physiological and growth responses of transplants of the moss Pseudoscleropodium purum to atmospheric pollutants. Water Air Soil Pollut. 2013;224. DOI: 10.1007/s11270-013-1753-4.

[45] Urošević MA, Vuković G, Jovanović P, Vujičić M, Sabovljević A, Sabovljević M, et al. Urban background of air pollution: Evaluation through moss bag biomonitoring of trace elements in Botanical garden. Urban Urban Green. 2017;25:1-10. DOI: 10.1016/j.ufug.2017.04.016.

[46] Chen YE, Wu N, Zhang ZW, Yuan M, Yuan S. Perspective of monitoring heavy metals by moss visible chlorophyll fluorescence parameters. Front Plant Sci. 2019;10:1-7. DOI: 10.3389/fpls.2019.00035.

[47] Charron AJ, Quatrano RS. Between a rock and a dry place: The water-stressed moss. Mol Plant. 2009;2:478-86. DOI: 10.1093/mp/ssp018.

[48] Stanković JD, Sabovljević AD, Sabovljević MS. Bryophytes and heavy metals: A review. Acta Bot Croat. 2018;77:109-18. DOI: 10.2478/botcro-2018-0014.

[49] Sokołowska K, Turzańska M, Nilsson MC. Symplasmic and apoplasmic transport inside feather moss stems of Pleurozium schreberi and Hylocomium splendens. Ann Bot. 2017;120(5):805-17. DOI: 10.1093/aob/mcx102. 